\title{
Report on technical activities and technical plan for university advanced manufacturing work for in-pile sensors
}

M. D. McMurtrey, G. llevbare, I. Van Rooyen

September 2017 
INL/EXT-17-43410

\title{
Report on technical activities and technical plan for university advanced manufacturing work for in-pile sensors
}

\author{
M. D. McMurtrey, G. llevbare, I. Van Rooyen
}

September 2017

\author{
Idaho National Laboratory \\ Idaho Falls, Idaho 83415
}

http://www.inl.gov

Prepared for the U.S. Department of Energy Office of Nuclear Energy Under DOE Idaho Operations Office

Contract DE-AC07-05ID14517 


\section{Report on technical activities and technical plan for university advanced manufacturing work for in-pile sensors}

\section{Executive Summary}

The In-Pile Initiative is working to develop and deploy novel instrumentation that may be used to characterize and monitor the behavior of fuels and materials within a nuclear reactor core during operation. The extreme conditions (temperature, environment, irradiation, etc.) make measurements difficult, which has resulted in typical characterizations being performed post-irradiation. This initiative has been divided into a number of work packages, with the focus of this work package being the development of advanced manufacturing techniques to support to novel sensor designs of the other work packages. This work is being performed at Idaho National Laboratory in collaboration with groups at both the University of Notre Dame and Boise State University. This report details the technical plans for the university work to address the goals of this work package.

To accelerate sensor research and development for in-pile measurements, the University of Notre Dame will focus on the development of an advanced additive manufacturing method, direct ink writing (DIW), to fabricate sensors of various designs and functions (including sensors with multiple functions). Their work is divided into two main objectives: 1) The development of direct-ink writing additive manufacturing equipment, process monitoring and control, and 2) the development of new materials processing and characterization methodologies for additive manufacturing. In the second objective, the work at the University of Notre Dame will be supporting the work of Boise State University as they develop new inks for printing sensors. The work being performed at Boise State University is divided into four objectives: 1) Nuclear grade nanoparticle ink synthesis, 2) advanced manufacturing process control through computer simulation, 3) prototypical surrogate sample development (to simulate fuel) for advanced manufacturing and 4) advanced manufacturing process qualification for the direct write inks. The modelling and simulation work in objective 2 will support the process sensing and control work being performed at the University of Notre Dame. 


\section{Report on technical activities and technical plan for university advanced manufacturing work for in-pile sensors}

\section{Introduction}

The ability to collect real time data from within a nuclear reactor core is key to running safe and efficient reactors. It is important, therefore, to have in-pile (within the reactor core) measurements on fuels and materials to provide the real time data during operation. These in-pile measurements provide significant more information than post irradiation examination and provide information on core conditions, monitoring issues as they form and resolve and providing input for core models and simulations. However, due to the extreme environments (high temperatures, irradiation), it is difficult to place and use sensors within the reactor. To this end, the In-Pile Instrumentation Initiative is working towards developing ultrasonic, optical, electromagnetic, and other sensors that function reliably in these harsh conditions, to provide real-time, accurate and spatially resolved information regarding performance of fuels and materials that can be directly tied to microstructure while the material/component is in-pile. This initiative is divided into a number of work packages, each focusing on portions of the overall objectives. The majority of these work packages strive to achieve breakthroughs in areas such as materials science, modeling and simulation, advanced manufacturing and instrument development.

This work package (Work Package 4 (WP4)) focuses not on developing a single type of sensor for a given in-pile application, but rather on the use of advanced manufacturing techniques to improve inpile sensors across the board through state-of-the-art sensor manufacturing methods. Advanced manufacturing, such as powder metallurgy based techniques, additive manufacturing (AM), or aerosol jet printing (AJP), have the potential to dramatically change in-pile sensors. Benefits over traditional manufacturing include the ability to create complex shapes without welded or soldered joints, to create seamless functionally graded material (transitioning from one material or alloy to another), create less waste of precious material used in sensor creation (such as platinum), quickly create small batches of prototypes during sensor development, and to integrate sensors directly onto fuel assemblies. There are a number of challenges that impede the full implementation of advanced manufacturing techniques, however. Currently, there are limits in what types of materials may be used in many of the advanced techniques. In the case where materials can be used, there is a lack of experience and guidelines/standards in using these techniques, which may potentially lead to poor replication and/or reliability of the resulting sensors. Some advanced techniques may also be slower than traditional techniques, resulting in low manufacturing throughput.

This work will initially focus on AJP. The demand for novel electronic devices with increased functionality and reduced footprints is driving innovations in advanced manufacturing methods that integrate electronic circuits directly onto physical packaging. One such method with emerging industrial impact is AJP. This additive manufacturing technique has recently been used to print conformal sensors, antennas, shielding and other active and passive components within the cellular telephone and aerospace industries.[1,2] Typical AJP materials include metals such as gold, silver, and nickel, as well as insulators such as polyimide and Su-8 [3,4]. However, the database of materials available for AJP is rapidly expanding and benefitting greatly from emerging nanomaterials development, e.g. development of graphene based inks [5]. Such rapid advancements in additive manufacturing will further enable direct printing of electronics and energy storage/conversion devices onto 3-dimensional substrates, proving beneficial to the instrumentation and controls of next generation reactors. 


\section{Needs and Roadblocks}

In order to better assess needs, a survey of available equipment amongst collaborators (INL, BSU, and UND) was performed and, is shown in Appendix 1. As a first step in this work, the ideal or useful advanced manufacturing techniques for creating sensors were identified. Due to the wide variety of sensor types (e.g. nanoscale neutron flux sensors, melt wires, thermocouples, solid-state thermistor, LVDTs, 3 omega sensors, as well as a variety of optical and ultrasound based sensors), and the complexity of each component and transducer within these sensors, it is possible that multiple techniques may be employed for the different sensors. This work will target and focus on the most versatile techniques across all the sensors being examined within this project that may benefit from advanced manufacturing.

No matter the chosen technique, development will need to occur to overcome limitations within the technique, such that it may fully be applied towards the needed sensor development. Typical shortcomings of advanced manufacturing, such as speed/manufacturing throughput will need to be addressed. It may also be necessary to include materials such as gold, silver, platinum, tungsten, cobalt, as well as other metals which are already typically employed in most advanced techniques (iron, copper, nickel) to increase material capability. There are often severe size constraints with deployment of in-pile sensors, so manufacturing techniques must be able to form materials at very small length scales, ideally with resolutions as low as $10 \mu \mathrm{m}$. Additionally, some sensors limit the form of manufacturing available due to heat sensitivity in the substrate, which may be damaged if too much heat or force is applied during sensor fabrication. For all advanced manufacturing techniques, there is a need for improved monitoring and control during the fabrication process. Any sensors formed using advanced techniques will need to be characterized and qualified against traditionally fabricated sensors and for the intended application. Additionally, advanced manufacturing must address the need to integrate sensors within nuclear fuel, with the expectation of optimal functionality regardless of neutron flux variations or other properties that may affect the durability and operation of such sensors.

One of the greatest needs being considered in this work for advanced manufacturing is the ability to monitor and control the process during fabrication. This is key to ultimately creating the desired material characteristics/sensor properties of the fabricated sensor, as well as realizing reliable and repeatable sensor fabrication. Typically there is very limited in-situ process sensing feedback and control in commercially available advanced manufacturing equipment, not enough to monitor and control all properties and phenomena that affect the fabricated piece. To this end, custom "in-house" capabilities will need to be developed that allow for the use of additional sensors and controls.

As described in the original work package scope, this work has begun by considering and developing Aerojet techniques for ceramic sensor production. A list (not exhaustive) of needed sensors and their manufacturing requirements using Aerojet techniques is shown in Appendix 2. There are a number of specific needs to this technique that are being considered and addressed. In order to fabricate graded material and multifunctional sensors, multi-nozzle printer heads will need to be developed, as well as the ability to integrate multiple processes during a single build. Similar to other techniques, Aerojet techniques will require the development of new printable materials with strict controls on particle size, shape and surface chemistry. While much of the needed equipment exists within the collaboratory (see Appendix 1), some capabilities will need to be added to address some of the sensor needs, such as the AJP-5X, which adds conformal printing capabilities. Additionally there is a need to bring additional advanced manufacturing capabilities to INL, the form of which is still under consideration based on further evaluation of sensor development needs from other work packages. It is expected that some the capabilities to be brought to INL will include advanced Laser Engineered Net-Shaping (LENS) 
equipment for fabricating wires for sensors. A fully developed list of required INL capabilities will be provided in the near future.

\section{Path Forward}

\section{University of Notre Dame}

Work at the University of Notre Dame has been focused on developing a custom, advanced direct ink writing (DIW) AM machine. The goal of this advancement in the technique is to be able to print fully integrated sensors with functional graded material onto or within the fuel assembly with minimal disruption, thus addressing some of the current roadblocks to in-pile sensor implementation. The machine will implement multiple printer heads to achieve some of those goals. This work will include the development of process sensing, control and modeling for DIW AM. A three dimensional finite element model is being developed to predict heating, cooling and particle sintering processes, which will ultimately help in determining process control values to achieve desired grain size, density and residual stresses of the printed material. Work is also progressing towards developing semiconductor, metallic and non-metallic nanoparticle inks for the AM process. Wet-chemical synthesis methods are being used to create large quantities of functionalized nanoparticles with controllable sizes and shapes. Nano-solder is being examined as a method to improve the sintering process. These research goals are described in more detail in the following paragraphs and divided among two objectives.

Objective 1: Development of direct-ink-writing additive manufacturing equipment, process monitoring and control

Task 1.1: Develop process sensing, control and modeling tools for DIW-AM.

The goal of this task is to develop in-situ sensing and control methods for ink delivery, deposition and sintering processes.

\section{$\underline{\text { Ink particle delivery sensing and control }}$}

An optoelectronic sensor will be developed to measure the particle delivery rate in real-time. When a laser beam passes through the particle stream in the carrier medium and enters the photo diode, the laser energy received by the photo diode decreases as the particle delivery rate increases due to diffusion, absorption and reflection as the laser beam interacts with the particles. A feedback control loop will be implemented to control and maintain the particle delivery rate at certain desired value, which can significantly improve the printed parts quality, size and shape control.

\section{$\underline{\text { Temperature sensing and energy delivery control for sintering process }}$}

Temperature sensing and energy delivery control are crucial to the AM sintering process. We will develop and implement a closed-loop infrared thermography system to monitor in-situ temperature and control the energy delivery during the sintering process. The infrared image collected by a high frame-rate infrared camera will be used to sense the temperature of the printed materials during sintering, and a feedback loop will be implemented to control the output power from the sintering energy source.

Modeling transient thermal behavior during sintering process

To fully understand the transient thermal behavior during sintering process, a three- dimensional finite element model will be developed to predict the heating, cooling and particle sintering processes based on the energy deposition and the cooling conditions. A complete understanding of the heating and 
cooling processes will offer us ultimate control of the grain size, density and residual stresses in the printed materials.

Task 1.2: Develop a versatile DIW-AM machine with integrated process monitoring and control.

It is extremely difficult to modify the commercial AM machines and implement process monitoring and control due to the hardware constraints and proprietary control software built in the machine. To overcome this challenge, UND will build a custom DIW-AM machine that provides open access to integrate the process monitor and control in order to realize fully optimized printing with predictable and repeatable performances. The majority of in-pile sensors require the integration of multiple materials, including semiconductor, metal and/or dielectric materials. Therefore, UND will integrate two to three printer heads capable of manufacturing multi-materials, multi-scale, and multifunctional in-pile sensors. Such an additive manufacturing equipment has the potential to print sensors embedded inside the fuel assembly, and bring revolutionary advances and unprecedented sensor manufacturing capability. An important area to be investigated under this thrust is using additive manufacturing techniques to integrate multimodal sensors (i.e., resistive, piezoelectric, thermoelectric) into a single instrument. For instance, temperature sensors that employ multiple methodologies (i.e., Seebeck effect and IR thermometry) can be integrated into a compact sensor module. This is critical to obtain accurate in-pile information because multi-physics phenomena can significantly influence measurement accuracy of a single mode sensor. Additionally, advanced manufacturing techniques will provide a diverse set of tools to develop and deploy an array of sensors that will enable significant improvements in spatial resolution, data quality, and measurement accuracy.

Deliverables (and dates) associated with objective 1:

1. An in-situ process sensing and control system for DIW-AM process (09/2018).

2. A process model to guide and optimize the AM processing parameters (03/2019).

3. A custom DIW-AM printer with integrated process sensing and control (03/2020).

Objective 2: Development of new materials processing and characterization methodologies for additive manufacturing.

Task 2.1: Design and bottom-up fabrication of colloidal nanoparticles for AM.

This task focuses on the design and development of semiconductor, metallic and non-metallic nanoparticle inks and their surface engineering for AM processes, and will be work on in conjunction with BSU. As shown in Figure 1, a bottom-up wet-chemical synthesis method will be used to rapidly synthesize large quantities of functionalized nanoparticles with controllable size and shape. Nanoparticle size plays an important role in the ink printing and sintering, as well as the resulting material properties. Reduced nanoparticle sizes are expected to have a lower melting point, [6] which would result in lower sintering temperature and denser printed structures. 


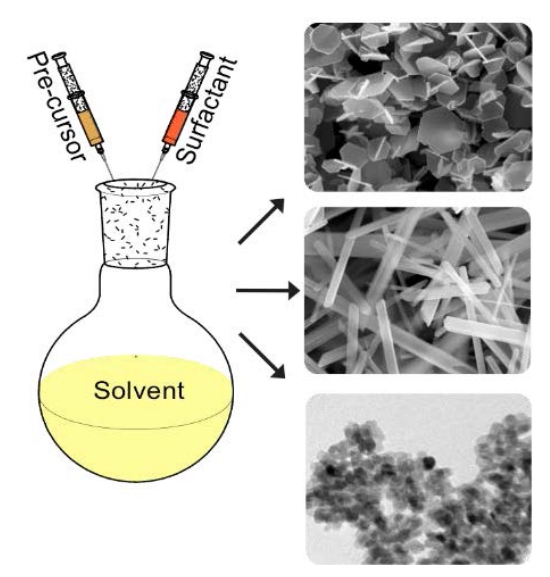

Figure 1. Colloidal nano-inks based on 2-D nanoplates, 1-D nanowires and 0-D nanoparticles synthesized using wet-chemical methods.

\section{Surface Engineering}

To preserve the nanoparticle property and translate it into device level performances, it is critical to prevent nanoparticle surface oxidation and control doping concentration throughout fabrication. Using an effective capping agent to limit nanoparticle surface oxidation is proposed to achieve this. Doing so will enable the storage and processing of nanoparticles in ambient air, as well as to synthesize inks, print films, and dry materials in ambient air.

\section{Interface Engineering}

The interfaces between nanoparticles play a pivotal role in printed materials $[7,8]$. At the same time, the physics and chemistry of interfaces in printed nanoparticles largely remain underexplored.[9] In materials printed from nanoparticle inks, the interfacial transport properties play an especially important role as these printed materials often suffer low density, and low energy carrier mobility due to poor connection between nanoparticles.[10] Hence, the use of a nano-solder approach by mixing the active sensor nanoparticles with a small percentage of nano-solders to facilitate sintering in the printed materials is proposed to achieve this (show in Figure 2).

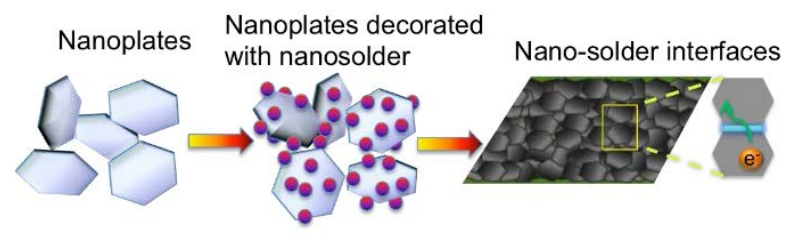

Figure 2. Nano-solder to facilitate sintering of printed materials

\section{Build functionally graded materials}

AM provides unprecedented control over the geometry, structure, and functions of the fabricated sensor materials and devices. [11] We propose to print a series of materials to build sensor components with functionally graded materials. The functionally graded materials enable us to control the composition and integrate multi-functionality into a single sensor device for accurate sensing and robust in-pile operation. For example, graded materials will be fabricated to integrate core sensor materials and other protective materials to enhance sensor corrosion and irradiation resistance. 


\section{Task 2.2: Characterization and qualification of AM fabricated sensor materials.}

It is critical to determine the properties and performances of printed sensors under the in-pile environment, especially under the high-temperature and high-irradiation conditions. The processingstructure-properties relationship of the printed sensors will be revealed using multi-scale experimental characterization and testing. Comprehensive characterization will be performed to study the contact/interface properties of dissimilar materials as a result of additive manufacturing methods and will be worked on in conjunction with BSU.

Notre Dame will study the printed materials performances before, during and after irradiation. Irradiation studies will be performed with Work Package 3 (WP3) when necessary. To accelerate this study, a high-throughput combinatory approach to investigate irradiation effect on large amount of materials compositions and processing conditions in a single process is proposed. For example, series of materials on a common substrate with different compositions and different laser sintering parameters can be printed to facilitate the investigation. Their properties before and after irradiation can then be mapped, and identification of the optimal materials composition and processing conditions that yield the highest irradiation resistance carried out. A unique scanning probe method developed by the UND PI will be used to map local thermal conductivity, Seebeck coefficient and other properties with micro/nanoscale resolution. $[12,13]$

Deliverables (and dates) associated with objective 2:

1. A wet-chemical bottom-up process to fabricate colloidal nanoparticle inks based on semiconductor, metal and metal oxides with controlled surface chemistry (09/2018).

2. A high-throughput approach to characterize and qualify AM printed materials for inpile application (09/2019).

\section{Boise State University}

BSU is focused on overcoming road blocks using commercially available aerosol inkjet printers. These commercial machines will be used to print new materials for formation of novel inks. Best practices for printing sensors will also be determined. Computer simulation, as well as experimental verification on prototypical surrogates samples that simulate fuel will be performed. This work has been divided into 4 objectives with associated tasks.

\section{Objective 1: Nuclear grade nanoparticle ink synthesis}

Developing an understanding of the performance of AJP materials in a nuclear environment will accelerate the modernization and enhanced functionality of the nuclear industry's sensors and instrumentation; in turn reducing effort and costs directed at maintaining obsolete controls systems. The goal of this objective is to establish a unique capability within the In-Pile Instrumentation Initiative framework to produce nanoparticle based nuclear grade inks compatible with a variety of additive manufacturing equipment. The proposed capabilities are captured schematically in Figure 3.

To accomplish this goal, three main tasks will be met, namely:

1.1. Syntheses and characterization of nanoparticle based inks

1.2. Printing and sintering synthesized inks

1.3. Qualification of inks as "nuclear grade" 


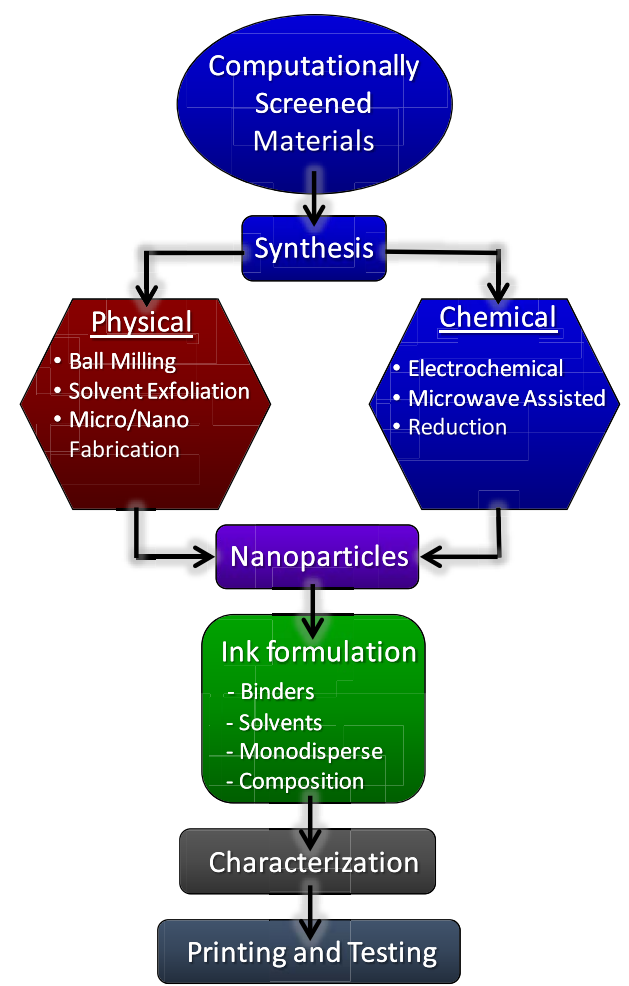

Figure 3. Proposed ink synthesis capabilities at BSU. Materials for additive manufacturing will be selected from computationally screened candidates and processed into nanoparticles chemically or physically. Equipment for chemical synthesis is available in the PI's laboratories. Nanoparticles are then formulated into powders and inks compatible with varying direct write technologies. Characterization of inks and their interactions with surfaces informs potential sensor applications and performance.

Task 1.1: Syntheses and characterization of nanoparticle based inks:

The enabling technologies of aerosol jet additive manufacturing are materials based inks. Therefore, with input from computational experts at BSU and INL, and in conjunction with UND, candidate sensor materials will be selected, and the team's significant experience in developing combinatorial nanoparticles based inks will be leveraged. $[15,16]$ Boise State University was recently awarded a NSUF Infrastructure grant to establish a centralized nanoparticle ink synthesis laboratory. The Boise State team will use this new facility to develop nanoparticle inks.

Ball milling will allow for pulverizing bulk materials and physical formation of metallic and ceramic nanoparticles. A glove box will allow the team to work with environmentally sensitive materials such as black phosphorus, and prevent or limit oxidation of metallic nanoparticles in a controlled atmosphere. A probe tip sonicator will aid in exfoliating layered materials and dispersing nanoparticles in various solvents resulting in a stable suspension for ink development. Nanoparticles will be sorted by size through density gradient ultracentrifugation in order to obtain monodisperse nanoparticle inks which have been correlated to higher performance devices.[17] The team will control ink concentration by forming nanoparticle powders and/or through exchanging solvents used for nanoparticle production with solvents that meet the viscosity requirements of various direct write systems.

Ink development requires screening nanoparticles and charactering ink properties. Therefore, the team will use a suite of instruments to characterize the ink properties. A particle size analyzer with Zeta 
potential measurement capability will provide information on the nanoparticles size distributions and the stability of the suspensions throughout the synthesis process. A tensiometer will provide fundamental information about ink interactions with various substrates, for example contact angle and surface energies, which impact ink spreading and printed feature resolution. Thermogravimetric/ differential scanning calorimetry analysis will be used to inform the melting temperatures and sintering conditions needed to remove binders, stabilizing polymers, and solvents. A rheometer will be used to characterize ink viscosity, and an optical microscope to characterize print quality.

The inks to be developed will be driven by the sensor needs. In the first year the team will focus on converting elemental nanoparticle dispersions into printable inks, and then on the bottom-up synthesis of alloy based inks for passive temperature sensors.

\section{Task 1.2: Printing and sintering of nanoparticle inks}

In order to evaluate the quality of our synthesized inks the team will test their compatibility with additive manufacturing equipment such as the Optomec AJP-200. Particular attention will be paid to ensuring that the inks have high enough nanoparticle concentrations to print continuous traces of material. Additional attention will be paid to understanding how the print parameters (\# passes, drop spacing, velocity, gas flows, etc.) and ink-substrate interactions (contact angle, surface energy, etc.) affect the structure of printed features. This task, especially the machine learning and process controls aspects will be carried out in collaboration with the UND team. This information will be provided to modeling and simulation teams in order to develop process control parameters for repeatable printing of nanoparticle based inks. In addition to traditional thermal sintering via hotplates and/or furnaces, the team will also investigate photonic sintering as a method to compact the deposited nanoparticles and form continuous features of fused nanomaterials. Photonic sintering has two major advantages over traditional thermal sintering: the sample can be effectively sintered without damaging the substrate and the ultrafast process can reduce grain growth and oxidation. [18]

\section{Task 1.3: Qualification of inks as "nuclear grade"}

The team will conduct a systematic irradiation campaign of electronic grade inks, enabling a sideby-side comparison of their irradiation behaviors with control samples made using standard manufacturing methods such as photolithography. This will be carried out on collaboration with Work Package 3 investigators. Qualification as a nuclear grade ink will depend on a targeted application. In general, the team define nuclear grade as the ability to print features/devices that survive high neutron flux and high operating temperatures. For example, in-pile ultrasonic thermometers should be able to survive a neutron flux $>1 \times 10^{12} \mathrm{n} / \mathrm{cm}^{2}$-s and a minimum operating temperature of $1000{ }^{\circ} \mathrm{C}$.[19] The team will investigate several families of computationally screened electronic materials including metals, semiconductors, and insulators. A graded approach to rapidly down select the materials library for advanced manufacturing of in-pile sensors will be used. Through this approach the team will first expose printed materials to ion irradiation in order to select only the most robust materials for follow on neutron irradiation studies. Based on ion irradiation results, robust electronic materials will be select, and their irradiation behaviors at low $\left(\sim 1 \times 10^{11} \mathrm{n} / \mathrm{cm}^{2}\right.$-s $)$, moderate $\left(1 \times 10^{11}-1 \times 10^{12} \mathrm{n} / \mathrm{cm}^{2}-\mathrm{s}\right)$, and high $\left(>1 \times 10^{12}\right.$ $\mathrm{n} / \mathrm{cm}^{2}-\mathrm{s}$ ) neutron flux will be investigated. To understand the fundamental mechanisms of potential radiation damage, the team will employ several techniques to characterize microstructure and property changes of the printed materials before and after irradiation. Samples will be configured for structural analysis through transmission electron microscopy (TEM), as well as configured for electrical and thermal transport characterization. Such post-irradiation examination (PIE) of samples will include TEM to characterize irradiation-induced microstructural changes. TEM will be performed at the Center for 
Advanced Energy Studies (CAES), and if needed in the Electron Microscopy Lab (EML) or the Irradiated Materials Characterization Laboratory (IMCL) at the INL Materials Fuels Complex (MFC). Post irradiation examination (PIE) of electrical and thermal transport properties will be carried out using standard current-voltage sourcing equipment and electrical thermometry at BSU, and as needed at the INL MFC. Additional facilities access for irradiation and PIE will be pursued through the NSUF Rapid Turnaround Experiments (RTE) mechanism as appropriate.

\section{Deliverables (and dates) associated with objective 1}

1. Size selective chemical synthesis, microstructural and physical characterization of metal nanoparticles ( $\mathrm{Au}, \mathrm{Ag}, \mathrm{Ni}, \mathrm{Cu}$ and $\mathrm{Fe}$ ) (March 2018)

2. Development of a protocol for stabilizing nanoparticle based Inks (June 2018)

3. Printing and optimization of nanoparticle inks on test substrates (September 2018)

\section{Objective 2: Advanced manufacturing process control}

Customizing the structure and properties of aerosol jet printed materials requires a fundamental understanding of how printing process control determines ink adhesion, dispersion, and sintered microstructure. Molecular dynamics simulations can provide insight into key processing-properties relationships during AJP, particularly how ink/solvent combinations self-assemble on surfaces and how the microstructure of printed inks evolves during sintering. Two factors limit the predictive capabilities of molecular simulations. The first is how computational cost of a simulation relates to the number of atoms or simulation elements needed. Simulations with femtosecond $\left(10^{-15} \mathrm{~s}\right)$ time steps require millions of steps to access nanoseconds of simulated time, and the best-case scenario (cost) of performing one step scales $O(N \log (N))$ with the number of simulation elements $N$. In practice, the complex or empirical potentials needed to simulate realistic materials scale $O\left(N^{2}\right)$, so a doubling of system size requires a fourfold increase in simulation time. The second factor limiting simulations is the availability of interaction potentials that are validated for specific systems of interest or tuned to model the simplified degrees of freedom of coarse-grained models.

The goal of the process control subgroup is to guide AJP processing protocols through the advancement and implementation of molecular simulations. This will be tied closely to the work performed at UND to create a custom DIW with enhanced process sensing and control. To accomplish this goal, two main tasks will need to be met:

1. Advance prediction of printed ink structures

2. Validate models for sintered microstructure

\section{Task 2.1: Advance prediction of printed ink structures.}

To access the micro- to millimeter length scales over which nanoparticle inks are printed during AJP, coarse grained models and hardware acceleration with graphics processing units (GPUs) will be used. GPUs are computing elements that can be added to traditional CPU-based computers that permit orders of magnitude speedup of parallelizable computations [9-16]. The barrier to accelerating molecular models with GPU hardware is implementing the parallelizable algorithms to utilize the GPU's features. GPU-acceleration is now a common feature in MD simulation packages including HOOMD-Blue, LAMMPS, and AMBER, though relative speedups (2x-10x) vary from package to package [9, 10, 15-17]. The BSU team has significant expertise developing and leveraging new GPU-accelerated simulation schemes for coarse-grained models now used by HOOMD-Blue [18-20]. Modifications to the MARTINI 
force field [21-22] will be used and parameterized to model coarse polydisperse inks suspended in solvents. Solvents will be modeled implicitly through the MARTINI force fields or explicitly as hydrodynamics-preserving dissipative particle dynamics elements. [23] Simulations of solvated inks at surfaces will be equilibrated to measure surface tension, viscosity, and surface energies as a function of included binders, stabilizing polymers, and solvents. Models parameterized and validated against experimental measurements from Objective 1 will be used to propose process control optimized for desired ink dispersions.

\section{Task 2.2: Validate models for sintered microstructure}

Prior simulation work studying the evolution of printed ink structure during sintering has been limited to small particle sizes (2-7 nm diameter) and few thousand atoms [24-27]. The team will leverage GPU acceleration of metal and metal-oxide models to investigate the sintering dynamics of polydisperse particle aggregates observed in experiments (5.A) or predicted from coarse-grained simulations. Here, systems of up to 300,000 atoms will be benchmarked and evaluated for their relaxation times and structural evolution. Conductivities between sintered conductive particles (e.g., Ag) will be calculated as a function of their neck sizes using the Reimann-Weber formula

$$
\sigma_{e}=\sigma_{b}\left(\frac{1}{x}+\frac{1}{\pi} \ln \frac{2}{x}\right)
$$

where $\sigma_{e}$ is the effective conductivity, $\sigma_{b}$ is the bulk conductivity of the metal, and $x$ is the neck diameter between sintered particles. Measured conductivity as well as AFM imaging of sintered surfaces will be used to validate model predictions. Matching nanoparticle polydispersity to experiments will enable for the first time the complex sintered microstructure of polydisperse inks to be investigated with molecular simulation. The validated simulations leveraging Buckingham or embedded atom model (EAM) potentials will be used to determine ink polydispersity indexes, solvent qualities, and sintering schedules that result in wetted surfaces with aggregated inks that sinter into microstructures with pore size distributions optimized for high temperature, high neutron flux applications.

\section{Deliverables (and dates) associated with objective 2}

1. Benchmark sintering simulations with for silver nanoparticles and coating simulations (June 2018)

2. Quantify differences in simulated and aerosol jet printed material conductivities and microstructures (September 2018)

3. Using combined experimental and computational approach, extract the important AM processing criteria that will inform AM process qualification for the nuclear industry (September 2018)

\section{Objective 3: Prototypical Surrogate Sample (to simulate fuel) Development for Advanced Manufacturing}

Throughout this In-Pile Instrumentation Initiative, there is a need for prototypic surrogate sample development to simulate fuel, not only for the Advanced Manufacturing Thrust, but also for many of the other sensor development and deployment activities within the initiative. However, working with uranium-containing materials increases the cost and time necessary to validate the novel instrumentation concepts. Therefore, it is worthwhile to consider surrogate fuel systems to decrease the innovation time and screen plausible AM instrumentation developments without the necessity of an NRC license and radioactive materials handling training. 
A literature review was conducted to identify appropriate surrogate materials in support of nuclear fuel research and development efforts such as fabrication and structural studies, understanding thermophysical properties, and irradiation behavior of nuclear fuel forms. Uranium dioxide $\left(\mathrm{UO}_{2}\right)$ continues to remain the benchmark and most widely used nuclear fuel [1-6] although transuranic mixed oxide (TRU/MOX) fuels have also been considered under the Advanced Fuel Cycle (AFC) program. TRU/MOX fuels are traditionally a blend of uranium and plutonium oxides although fuels with high amounts of other transuranics such as neptunium, americium, and curium have also been considered TRU/MOX. [10, 15-17]

Cerium Oxide $\left(\mathrm{CeO}_{2}\right)$ as a surrogate for plutonium oxide $\left(\mathrm{PuO}_{2}\right)$ and uranium oxide $\left(\mathrm{UO}_{2}\right)$

Obvious impediments to investigating and processing nuclear fuel forms involving plutonium, or its oxide, plutonia $\left(\mathrm{PuO}_{2}\right)$, include the risks from toxicity, radioactivity, and proliferation concerns. [10,16-19] Cerium oxide $\left(\mathrm{CeO}_{2}\right)$ has been used historically as an inactive $\mathrm{PuO}_{2}$ surrogate, most commonly in studies of TRU/MOX fuels in the form of $(\mathrm{U}, \mathrm{Ce}) \mathrm{O}_{2}$ solid solutions as well as a plutonia analog in (Th,Ce) $\mathrm{O}_{2}$ systems) $[10,14,16-29]$. Some of the characteristics which make $\mathrm{CeO}_{2}$ a viable surrogate for $\mathrm{PuO}_{2}$ are that $\mathrm{Ce}$ and $\mathrm{Pu}$ have similar ionic size in octahedral and cubic coordination, and their oxides in $3^{+}$and $4^{+}$valence states have similar melting temperatures, standard enthalpies of formation, and specific heat capacities [10, 22, 30-31]. $\mathrm{CeO}_{2}, \mathrm{PuO}_{2}$, and $\mathrm{UO}_{2}$ all possess the same fluorite structure $\left(\mathrm{CaF}_{2}, \mathrm{Fm} \overline{3} \mathrm{~m}\right)$, resulting in the ability to form mixed oxide solid solutions $[10,16]$. Based on these attributes, a range of studies regarding the thermophysical properties (thermal expansion, heat capacity, thermal conductivity, and thermodynamic stability) of $\mathrm{CeO}_{2}$ as a surrogate fuel have been undertaken [10, 14, 16-21, 23, 24, 26-28].

Investigations of thermal diffusivity via laser flash analysis (LFA), linear thermal expansion by dilatometry, and specific heat capacity from differential scanning calorimetry (DSC) allowed for the calculation of thermal conductivity of stoichiometric $\mathrm{CeO}_{2}$ and solid solution (U,Ce) $\mathrm{O}_{2}$ samples $[10,16$, $23,26]$. Nelson et al. concluded that in the temperature range relevant to nuclear fuels, there is a significant difference in the thermal conductivities of stoichiometric $\mathrm{PuO}_{2}, \mathrm{UO}_{2}$, and $\mathrm{CeO}_{2}$, with $\mathrm{PuO}_{2}$ being the highest and $\mathrm{CeO}_{2}$ the lowest. The work by $\mathrm{H}$. Kim et al. indicated Pu-MOX fuel had only a slightly higher thermal conductivity than the Ce-MOX fuel at lower temperatures, but the values overlapped above $900 \mathrm{~K}$, and that thermal conductivity decreased with increasing Ce content in the solid solutions, which agrees with the study by D. Kim et al. who attributed this to increasing lattice defect thermal resistance caused by ions acting as point defects [10, 16,23]. This was also pointed out by Nelson et al. in that the thermal transport properties of insulators are highly sensitive to defect structures. They noted that because $\mathrm{CeO}_{2}$ will readily reduce in air at typical experimental temperatures, introducing $\mathrm{CeO}_{2}$ into composites or alloys which reduces the oxygen activity will initiate vacancies that will further degrade the thermal conductivity of $\mathrm{CeO}_{2}$, thus potentially underestimating thermal transport behavior of composite systems using $\mathrm{PuO}_{2}$. [10]

As noted by Kato in 2012, the variation in the stoichiometry of MOX fuels affects various properties like lattice parameter, melting temperature, and thermal conductivity resulting in several studies on the oxygen to metal (O:M) ratio dependence of oxygen potential [14, 19, 25, 28]. These fuels can exist over a wide range of $\mathrm{O}: \mathrm{M}$ ratios and the literature regarding the correlation of calculations of oxygen potential in $(\mathrm{U}, \mathrm{Pu}) \mathrm{O}_{2}$ to $(\mathrm{U}, \mathrm{Ce}) \mathrm{O}_{2}$ is limited and scattered due to the difficulty in measuring oxygen potential near the stoichiometric region [14]. The literature suggests that while similarities exist regarding the dependence of oxygen potential and lattice parameter on the O:M ratio, there are also differences, such as the oxygen potential at a given temperature being a function of plutonium valence, which will not apply to cerium $[14,28]$. Work by Byler et al. investigated the effect of oxygen potential 
on the sinterability and thermophysical properties of ceria by tracking the O:M ratio as a function of temperature, partial pressure of oxygen $\left(\mathrm{pO}_{2}\right)$, and heating rates, suggesting that strict control of $\mathrm{pO}_{2}$ is essential for controlling O:M ratios and thus identification of proper sintering paths. [25]

$\mathrm{CeO}_{2}$ as a surrogate for $\mathrm{UO}_{2}$ has also been examined in relation to basic structural and fabrication studies and more extensively as an analog in irradiation behavior [10-13, 32-42]. $\mathrm{CeO}_{2}$ has been shown to be an adequate analog to $\mathrm{UO}_{2}$ for many of the same reasons as listed above for $\mathrm{PuO}_{2}$ (i.e. same crystal structure, similar thermal and mechanical properties) and it is more easily managed for research labs which are not able to utilize radioactive materials $[10,11,32,33]$.

Conventional pressureless sintering parameters for pure $\mathrm{CeO}_{2}$ and $\mathrm{Ce}-\mathrm{MOX}$ samples as described in the above referenced literature ranged from $1200-1750{ }^{\circ} \mathrm{C}$ for $2-48$ hours. The most commonly used sintering atmosphere was static air, however, a few studies did employ pure $\mathrm{O}_{2}$ for comparison, and $\mathrm{CO}_{2}$ followed by $\mathrm{N}_{2}+8 \% \mathrm{H}_{2}$, and humidified $\mathrm{Ar}+8 \% \mathrm{H}_{2}$ (for controlling $\mathrm{UO}_{2}$ stoichiometry) [10, 11, 16, 21, 23, $24,26,29,32,33,35,36,38,43-45]$. Only the study by Torres et al. discussed controlling porosity as a function of binder percentage [33]. Other non-fuels related literature on conventional sintering of $\mathrm{CeO}_{2}$ used sintering temperatures, dwell times, and atmospheres similar to those already mentioned, but also included considerations for grain growth by the addition of dopants, as noted in work by Rahaman, Zhou, and Chen. Specifically, the use of undersized cation dopants such as $\mathrm{Mg}, \mathrm{Sc}, \mathrm{Ti}$, and $\mathrm{Nb}$ [46-48] were discussed. Podor et al. also referenced the influence of $\mathrm{pO}_{2}$ on the final $\mathrm{CeO}_{2}$ stoichiometry [49]. O'Brien et al. investigated the use of spark plasma sintering for $\mathrm{CeO}_{2}$ as a surrogate to $\mathrm{PuO}_{2}, \mathrm{UO}_{2}$, and $\mathrm{AmO}_{2}$ in tungsten cermets [42].

Depleted uranium oxide (d- $\left.\mathrm{UO}_{2}\right)$ as a surrogate for $\mathrm{UO}_{2}$

Use of depleted uranium oxide $\left(\mathrm{d}-\mathrm{UO}_{2}\right)$ simplifies research studies of $\mathrm{UO}_{2}$ as compared to $\mathrm{PuO}_{2}$. A variety of studies using $\mathrm{d}-\mathrm{UO}_{2}$ as a $\mathrm{UO}_{2}$ surrogate exist spanning a wide range of topics, only a few of which are referenced here for brevity. These include synthesis of thin $\mathrm{UO}_{2}$ films from electron beam evaporation of $\mathrm{UO}_{2}$ pellets, mechanical properties of nuclear fuel surrogates using picosecond laser ultrasonics, characterization of minor actinide MOX fuel, microstructural evolution of simulated high burn-up structures, synthesis and sintering of nitride-oxide composites, and Raman spectroscopy for corrosion product identification on $\mathrm{UO}_{2}[15,50-54]$.

As discussed previously, the O:M ratio in nuclear fuel is important in understanding its performance. An approach to determine the partial pressure of oxygen in the process gas to bring an oxide into stoichiometric equilibrium at a given temperature was developed by Ellingham [55, 56]. For conventional sintering of d-UO ${ }_{2}$, generally high temperatures $\left(1700^{\circ} \mathrm{C}\right)$ in a reducing atmosphere (e.g. $\mathrm{H}_{2}$ ) although lower sintering temperatures is desired for reduction of manufacturing costs [57]. Harada (1997) showed that dense, large-grained $\mathrm{UO}_{2}$ pellets could be obtained when using a three-stage sintering profile between $1200-1500{ }^{\circ} \mathrm{C}$, consisting of reducing-oxidizing-reducing atmospheres and the oxygen partial pressure was controlled to be at the maximum corresponding to the boundary between the singlephase region $\mathrm{UO}_{2+\mathrm{x}}$ and the two-phase region $\mathrm{UO}_{2+\mathrm{x}}-\mathrm{U}_{3} \mathrm{O}_{8-\mathrm{z}}$. and sinterability was independent of the starting O:M ratio [57].

Based on this review, the objective of this work stream is to develop a set of prototypical surrogate samples to simulate fuels, on which validation of the performance of the sensors produced via advanced manufacturing techniques will be carried out.

Prototypic fuels and materials with well-known physical and thermal characteristics (e.g. grain microstructure, phase distribution, stoichiometry (O:M ratio), porosity, thermal diffusivity, etc.) will be 
used as substrates for the advanced manufacturing of innovative instrumentation. In this work package, fuels (surrogate oxide fuels, such as cerium oxide $\left(\mathrm{CeO}_{2}\right)$ and depleted uranium oxide $\left(\mathrm{d}-\mathrm{UO}_{2}\right)$ as well as depleted uranium (d-U) metal fuels) will be fabricated with varied properties.

Single-phase oxide fuels will be fabricated by milling commercially available surrogate oxides, such as d- $\mathrm{UO}_{2}$ and $\mathrm{CeO}_{2}$ in a Retsch PM100 planetary ball mill. The final particle size of the mixed powders can be carefully controlled from sub-micrometer to tens of micrometers through the control of the starting powder size and milling conditions (milling intensity, milling time, powder-to-media ratio, media morphology and density, and wet versus dry milling). The phase of the powders will be characterized using XRD (Rigaku Miniflex) and morphology will be investigated using SEM and TEM imaging practices in the Boise State Center for Materials Characterization (BSCMC). Particle size distribution will be quantified using a Horiba LA-950 laser scattering particle size analyzer and the surface area of the powder will be quantified using a Quantachrome Nova 2200e surface area and pore size analyzer. Simultaneous thermogravimetric analysis and differential scanning calorimetry (TGA/DSC) will be completed using a Netzsch STA 449 to perform loss on ignition (LOI) analysis on the powders and to identify suitable calcining temperatures and atmospheres. In the case of $\mathrm{d}-\mathrm{UO}_{2}$ powder handling and processing, an inert atmosphere glovebox and bagging techniques will be used.

Powders will be calcined in controlled atmosphere furnaces (or air furnaces where applicable) prior to sintering. The powders will be cold-pressed using a pellet die set in a Carver hydraulic ram pellet press to produce green pellets $(\approx 15 \mathrm{~mm}$ diameter). The green pellets will be sintered in a controlled atmosphere alumina vacuum tube furnace (CM Furnaces) up to $1700^{\circ} \mathrm{C}$ with precisely controlled and monitored oxygen and water concentrations to control the $\mathrm{O}: \mathrm{M}$ ratio. The sintered pellets will have a target diameter and density of approximately $12.2 \mathrm{~mm}$ and $10.6 \mathrm{~g}-\mathrm{cm}^{-3}$. Additional heat treatments to increase grain size will be completed in a refractory metal furnace (Thermal Technologies). The density of the pellets will be determined using an Archimedes method and the phase purity will be characterized using XRD (Rigaku Miniflex). Chemical analysis will be investigated using XRF, SEM/EDS and TEM/EELS the BSCMC, if necessary. Grain size and other physical and chemical properties will be characterized using optical techniques, as well as SEM and TEM techniques, including EBSD and ASTAR, if necessary. A combined effort of LECO and thermogravimetry will be used to assess the O:M of the prototypic surrogate fuel pellets.

\section{Deliverables (and dates) associated with objective 3}

1. Procure and fully characterize precursor powders for surrogate fuel fabrication (December 2018)

2. Procure precursor powders for $\mathrm{d}-\mathrm{UO}_{2}$ fuel fabrication (May 2019)

3. Fabricate and characterize prototypic surrogate $\left(\mathrm{CeO}_{2}\right)$ fuel pellets (September 2019)

\section{Objective 4: Advanced manufacturing process qualification}

This objective of this work stream is to take the output from AM process control and develop the environmental qualification protocols that will lead to in-pile instrumentation standardization and wide spread adoption into the nuclear industry. To achieve this objective, the team will work closely with INL counterparts to develop an AM Process Qualification plan with the Nuclear Regulatory Commission.

\section{Deliverables (and dates) associated with objective 4}

1. Develop the environmental qualification protocols to standardize in-pile instrumentation (June 2019) 


\section{References}

1. OECD/NEA IAEA, Uranium 2014: Resources, Production, and Demand, Paris, 2014.

2. A.T. Nelson, D.R. Rittman, J.T. White, J.T. Dunwoody, M. Kato, K.J. McClellan, An evaluation of the thermophysical properties of stoichiometric $\mathrm{CeO} 2$ in comparison to $\mathrm{UO} 2$ and $\mathrm{PuO} 2$, J. Am. Ceram. Soc. 97 (2014) 3652-3659. http://10.0.4.87/jace.13170.

3. J. Roleček, Š. Foral, K. Katovský, D. Salamon, A feasibility study of using $\mathrm{CeO} 2$ as a surrogate material during the investigation of UO2 thermal conductivity enhancement, Adv. Appl. Ceram. 116 (2017) 123-131. doi:10.1080/17436753.2016.1264122.

4. B. Ye, A. Oaks, M. Kirk, D. Yun, W.-Y. Chen, B. Holtzman, J.F. Stubbins, Irradiation effects in UO2 and CeO2, J. Nucl. Mater. 441 (2013) 525-529. doi:10.1016/j.jnucmat.2012.09.035.

5. H. Ohno, A. Iwase, D. Matsumura, Y. Nishihata, J. Mizuki, N. Ishikawa, Y. Baba, N. Hirao, T. Sonoda, M. Kinoshita, Study on effects of swift heavy ion irradiation in cerium dioxide using synchrotron radiation X-ray absorption spectroscopy, Nucl. Instruments Methods Phys. Res. Sect. B Beam Interact. with Mater. Atoms. 266 (2008) 3013-3017.

6. Buffat, P. \& Borel, J. P. Size Effect on Melting Temperature of Gold Particles. Phys Rev A 13, 2287-2298 (1976).

7. Kim, W., Wang, R. \& Majumdar, A. Nanostructuring expands thermal limits. Nano Today 2, 4047 (2007).

8. Snyder, G. J. \& Toberer, E. S. Complex thermoelectric materials. Nat Mater 7, 105-114 (2008).

9. Yang, J. H., Yip, H. L. \& Jen, A. K. Y. Rational Design of Advanced Thermoelectric Materials. Adv Energy Mater 3, 549-565 (2013).

10. Dolzhnikov, D. S. et al. Composition-matched molecular "solders" for semiconductors. Science 347, 425-428 (2015).

11. Huang, Y., Leu, M. C., Mazumder, J. \& Donmez, A. Additive Manufacturing: Current State, Future Potential, Gaps and Needs, and Recommendations. J Manuf Sci E-T Asme 137 (2015).

12. Zhang, Y., Castillo, E. E., Mehta, R. J., Ramanath, G. \& Borca-Tasciuc, T. A noncontact thermal microprobe for local thermal conductivity measurement. Rev Sci Instrum 82 (2011).

13. Zhang, Y. et al. A microprobe technique for simultaneously measuring thermal conductivity and Seebeck coefficient of thin films. Applied Physics Letters 96 (2010).

14. M. Kato, Oxygen potentials and defect chemistry in nonstoichiometric (U, Pu) O2, in: Stoichiom. Mater. Sci. Numbers Matter, InTech, 2012.

15. A.D. Neuman, C.C. Davis, T.A. Nothwang, F.G. Hampel, S.L. Voit, M.R. Lopez, A.C. Martinez, Characterization of minor actinide mixed oxide fuel, J. Nucl. Mater. 385 (2009) 168-172.

16. H.S. Kim, C.Y. Joung, B.H. Lee, J.Y. Oh, Y.H. Koo, P. Heimgartner, Applicability of CeO 2 as a surrogate for PuO 2 in a MOX fuel development, J. Nucl. Mater. 378 (2008) 98-104.

17. S.L. Voit, T.M. Besmann, Thermochemical Modeling of the Uranium-Cerium-Oxygen System, Oak Ridge National Laboratory (ORNL), 2010.

18. Y.S. Park, H.Y. Sohn, D.P. Butt, Thermal removal of gallium from gallia-doped ceria, J. Nucl. Mater. 280 (2000) 285-294. doi:10.1016/S0022-3115(00)00064-7.

19. K. Nagarajan, R. Saha, R.B. Yadav, S. Rajagopalan, K.V.G. Kutty, M. Saibaba, P.R.V. Rao, C.K. Mathews, Oxygen potential studies on hypostoichiometric uranium-cerium mixed oxide, J. Nucl. Mater. 130 (1985) 242-249.

20. Y. Altaş, H. Tel, Structural and thermal investigations on cerium oxalate and derived oxide powders for the preparation of (Th, Ce) O 2 pellets, J. Nucl. Mater. 298 (2001) 316-320.

21. M.D. Mathews, B.R. Ambekar, A.K. Tyagi, Bulk thermal expansion studies of Th1-xCexO2 in the complete solid solution range, J. Nucl. Mater. 288 (2001) 83-85. doi:10.1016/S00223115(00)00719-4.

22. S. V Chavan, M.D. Mathews, A.K. Tyagi, Phase Relations and Thermal Expansion Studies in the Ceria-Yttria System., J. Am. Ceram. Soc. 87 (2004) 1977-1980.

23. D.-J. Kim, Y.-S. Kim, S.-H. Kim, J.-H. Kim, J.-H. Yang, Y.-W. Lee, H.-S. Kim, The linear 
thermal expansion and the thermal diffusivity measurements for near-stoichiometric (U, Ce) O 2 solid solutions, Thermochim. Acta. 441 (2006) 127-131.

24. J. Blumm, D.D. Byler, T. Hartmann, J.B. Henderson, K.J. McClellan, E. Post, Characterization of cerium oxide during sintering, in: MS\&T, Pittsburgh, PA, 2009.

25. D.D. Byler, J.T. Dunwoody, J.B. Henderson, E.P. Luther, K.J. McClellan, A.T. Nelson, The effect of oxygen potential on the sinterability and evolution of the thermophysical properties of ceria, (2010).

26. R.V. Krishnan, K. Nagarajan, Heat capacity measurements on uranium-cerium mixed oxides by differential scanning calorimetry, Thermochim. Acta. 440 (2006) 141-145.

27. A. Nakamura, A defect-thermodynamic approach to $\mathrm{PuO} 2-\mathrm{x}$ and $\mathrm{CeO} 2-\mathrm{x}, \mathrm{J}$. Nucl. Mater. 201 (1993) 17-26.

28. D.I.R. Norris, P. Kay, Oxygen potential and lattice parameter measurements in (U, Ce) $\mathrm{O} 2-\mathrm{x}, \mathrm{J}$. Nucl. Mater. 116 (1983) 184-194.

29. G.W. Egeland, L.D. Zuck, W.R. Cannon, P.A. Lessing, P.G. Medvedev, Dry bag isostatic pressing for improved green strength of surrogate nuclear fuel pellets, J. Nucl. Mater. 406 (2010) 205-211. doi:10.1016/j.jnucmat.2010.08.022.

30. P.A. Bingham, R.J. Hand, M.C. Stennett, N.C. Hyatt, M.T. Harrison, The use of surrogates in waste immobilization studies: a case study of plutonium, MRS Online Proc. Libr. Arch. 1107 (2008).

31. R.J.M. Konings, O. Beneš, A. Kovács, D. Manara, D. Sedmidubský, L. Gorokhov, V.S. Iorish, V. Yungman, E. Shenyavskaya, E. Osina, The thermodynamic properties of the f-elements and their compounds. Part 2. The lanthanide and actinide oxides, J. Phys. Chem. Ref. Data. 43 (2014) 13101.

32. M.C. Stennett, C.L. Corkhill, L.A. Marshall, N.C. Hyatt, Preparation, characterisation and dissolution of a CeO 2 analogue for UO 2 nuclear fuel, J. Nucl. Mater. 432 (2013) 182-188.

33. Y. Torres, C. García-Ostos, C. Arévalo, F.J. Gotor, J.J. Pavón, P. Trueba, J.A. Rodríguez-Ortiz, Processing and characterization of surrogate nuclear materials with controlled radial porosity, J. Nucl. Sci. Technol. 54 (2017) 167-173.

34. A. Guglielmetti, A. Chartier, L. van Brutzel, J.-P. Crocombette, K. Yasuda, C. Meis, S. Matsumura, Atomistic simulation of point defects behavior in ceria, Nucl. Instruments Methods Phys. Res. Sect. B Beam Interact. with Mater. Atoms. 266 (2008) 5120-5125.

35. T. Sonoda, M. Kinoshita, N. Ishikawa, M. Sataka, Y. Chimi, N. Okubo, A. Iwase, K. Yasunaga, Clarification of the properties and accumulation effects of ion tracks in $\mathrm{CeO} 2$, Nucl. Instruments Methods Phys. Res. Sect. B Beam Interact. with Mater. Atoms. 266 (2008) 2882-2886. doi:10.1016/j.nimb.2008.03.214.

36. K. Yasunaga, K. Yasuda, S. Matsumura, T. Sonoda, Electron energy-dependent formation of dislocation loops in $\mathrm{CeO} 2$, Nucl. Instruments Methods Phys. Res. Sect. B Beam Interact. with Mater. Atoms. 266 (2008) 2877-2881.

37. T. Sonoda, M. Kinoshita, Y. Chimi, N. Ishikawa, M. Sataka, A. Iwase, Electronic excitation effects in $\mathrm{CeO} 2$ under irradiations with high-energy ions of typical fission products, Nucl. Instruments Methods Phys. Res. Sect. B Beam Interact. with Mater. Atoms. 250 (2006) 254-258. doi:10.1016/j.nimb.2006.04.120.

38. A. Iwase, H. Ohno, N. Ishikawa, Y. Baba, N. Hirao, T. Sonoda, M. Kinoshita, Study on the behavior of oxygen atoms in swift heavy ion irradiated $\mathrm{CeO} 2$ by means of synchrotron radiation X-ray photoelectron spectroscopy, Nucl. Instruments Methods Phys. Res. Sect. B Beam Interact. with Mater. Atoms. 267 (2009) 969-972.

39. K. Yasunaga, K. Yasuda, S. Matsumura, T. Sonoda, Nucleation and growth of defect clusters in $\mathrm{CeO} 2$ irradiated with electrons, Nucl. Instruments Methods Phys. Res. Sect. B Beam Interact. with Mater. Atoms. 250 (2006) 114-118.

40. H.K. Pappas, B.J. Heuser, M.M. Strehle, Measurement of radiation-enhanced diffusion of La in single crystal thin film CeO 2, J. Nucl. Mater. 405 (2010) 118-125. 
41. B. Ye, M.A. Kirk, W. Chen, A. Oaks, J. Rest, A. Yacout, J.F. Stubbins, TEM investigation of irradiation damage in single crystal CeO 2, J. Nucl. Mater. 414 (2011) 251-256.

42. R.C. O'Brien, R.M. Ambrosi, N.P. Bannister, S.D. Howe, H. V Atkinson, Spark plasma sintering of simulated radioisotope materials within tungsten cermets, J. Nucl. Mater. 393 (2009) 108-113.

43. T. Fujino, T. Shiratori, N. Sato, K. Fukuda, K. Yamada, H. Serizawa, Post-irradiation examination of high burnup $\mathrm{Mg}$ doped $\mathrm{UO} 2$ in comparison with undoped $\mathrm{UO} 2, \mathrm{Mg}-\mathrm{Nb}$ doped UO2 and Ti doped UO2, J. Nucl. Mater. 297 (2001) 176-205. doi:10.1016/S00223115(01)00609-2.

44. S.I. Ahmad, P.K. Rao, I.A. Syed, Sintering temperature effect on density, structural and morphological properties of Mg- and Sr-doped ceria, J. Taibah Univ. Sci. 10 (2016) 381-385. doi:10.1016/J.JTUSCI.2015.04.003.

45. H.J. Matzke, V.V. Rondinella, T. Wiss, Materials research on inert matrices: a screening study, J. Nucl. Mater. 274 (1999) 47-53. doi:10.1016/S0022-3115(99)00062-8.

46. M.N. Rahaman, Y.C. Zhou, Effect of solid solution additives on the sintering of ultra-fine $\mathrm{CeO} 2$ powders, J. Eur. Ceram. Soc. 15 (1995) 939-950.

47. Y.C. Zhou, M.N. Rahaman, Hydrothermal synthesis and sintering of ultrafine $\mathrm{CeO} 2$ powders, J. Mater. Res. 8 (1993) 1680-1686.

48. P. Chen, I. Chen, Grain growth in CeO2: dopant effects, defect mechanism, and solute drag, J. Am. Ceram. Soc. 79 (1996) 1793-1800.

49. R. Podor, N. Clavier, J. Ravaux, L. Claparede, N. Dacheux, In Situ HT-ESEM Observation of CeO2 Grain Growth During Sintering, J. Am. Ceram. Soc. 95 (2012) 3683-3690.

50. I.O. Usov, R.M. Dickerson, P.O. Dickerson, M.E. Hawley, D.D. Byler, K.J. McClellan, Thin uranium dioxide films with embedded xenon, J. Nucl. Mater. 437 (2013) 1-5.

51. D. Hurley, M. Khafizov, F. Farzbod, E. Burgett, Mechanical properties of nuclear fuel surrogates using picosecond laser ultrasonics, Idaho National Laboratory (INL), 2013.

52. T. Sonoda, M. Kinoshita, N. Ishikawa, M. Sataka, A. Iwase, K. Yasunaga, Clarification of high density electronic excitation effects on the microstructural evolution in UO 2, Nucl. Instruments Methods Phys. Res. Sect. B Beam Interact. with Mater. Atoms. 268 (2010) 3277-3281.

53. B.J. Jaques, J. Watkins, J.R. Croteau, G.A. Alanko, B. Tyburska-Püschel, M. Meyer, P. Xu, E.J. Lahoda, D.P. Butt, Synthesis and sintering of UN-UO2 fuel composites, J. Nucl. Mater. 466 (2015) 745-754. doi:10.1016/j.jnucmat.2015.06.029.

54. M. Amme, B. Renker, B. Schmid, M.P. Feth, H. Bertagnolli, W. Döbelin, Raman microspectrometric identification of corrosion products formed on UO 2 nuclear fuel during leaching experiments, J. Nucl. Mater. 306 (2002) 202-212.

55. H.J.T. Ellingham, Reducibility of oxides and sulfides in metallurgical processes, J. Soc. Chem. Ind. (1944) 125-133.

56. F.D. Richardson, J.H.E. Jeffes, The thermodynamics of substances of interest in iron and steel making from 0 C to 2400 C: I-Oxides, J. Iron Steel Inst. 160 (1948) 261.

57. Y. Harada, UO2 sintering in controlled oxygen atmospheres of three-stage process, J. Nucl. Mater. 245 (1997) 217-223. doi:10.1016/S0022-3115(96)00755-6. 


\section{APPENDIX A}

Table A1: Available equipment among collaborators (INL, BSU and UND)

\begin{tabular}{|c|c|c|c|}
\hline Category & Location & Equipment & Specifications \\
\hline Microscopy & INL & FEI Quanta 650 SEM & $\begin{array}{l}\text { Contains EDS, WDS, and EBSD } \\
\text { detectors } \\
\text { Heating stage, and a } \\
\text { micromechanical testing stage }\end{array}$ \\
\hline Microscopy & INL & JOEL JSM-6610V SEM & $\begin{array}{l}\text { Contains EDS, EBSD and CL } \\
\text { detectors }\end{array}$ \\
\hline Microscopy & INL & FEI Tecnai TF 30 G2 FEG TEM & $\begin{array}{l}\text { EDS, ASTAR, Hummingbird } \\
\text { heating stage }\end{array}$ \\
\hline Microscopy & INL & $\begin{array}{l}\text { Nikon } 5 \text { laser excitation } 32 \text { channel } \\
\text { spectrometer confocal microscope }\end{array}$ & Laser range from $400-640 \mathrm{~nm}$ \\
\hline Microscopy & INL & $\begin{array}{l}\text { Cameca Instruments Local electrode Atom } \\
\text { Probe } 4000 X \text { HR }\end{array}$ & $\begin{array}{l}\text { Atomic scale structural and } \\
\text { chemical analysis, both voltage } \\
\text { and laser mode of evaporation }\end{array}$ \\
\hline X-ray CT & INL & $\begin{array}{l}\text { North Star Imaging micro-focus X-ray CT } \\
\text { system }\end{array}$ & \\
\hline X-ray & INL & $\begin{array}{l}\text { Two Bruker D8 Advance X-ray diffraction } \\
\text { systems }\end{array}$ & \\
\hline $\begin{array}{l}\text { Additive } \\
\text { Manufacturing }\end{array}$ & BSU & Optomec 200 Aerosol Jet Printer & $\begin{array}{l}\text { Work area } 175 \mathrm{~mm} \times 200 \mathrm{~mm} \\
\text { Motion repeatability accuracy } \\
+/-5 \text { Microns } \\
\text { Feature sizes to } 10 \mathrm{um} \\
\text { Thin layer deposits of } 100 \mathrm{~nm} \\
\text { Ink viscosity range from } 1-1000 \\
\text { cP with optional Pneumatic } \\
\text { Atomizer }\end{array}$ \\
\hline $\begin{array}{l}\text { Additive } \\
\text { Manufacturing }\end{array}$ & BSU & Dimatix 2831 Materials Inkjet Printer & $\begin{array}{l}\text { Printable area: } \\
\text { Substrate }<0.5 \mathrm{~mm} \text { thick: } 210 \\
\mathrm{~mm} \times 315 \mathrm{~mm} \\
\text { Substrate } 0.5-25 \mathrm{~mm} \text { thick: } 210 \\
\mathrm{~mm} \times 260 \mathrm{~mm} \\
\text { Repeatability: } \pm 25 \mu \mathrm{m}( \pm 0.001 \\
\text { in) } \\
\text { Feature sizes to } 25 \mathrm{um} \\
\text { Ink viscosity range from } 1-10 \mathrm{cP}\end{array}$ \\
\hline $\begin{array}{l}\text { Additive } \\
\text { Manufacturing }\end{array}$ & $\mathrm{BSU}$ & Xenon Sinteron 2100 & $\begin{array}{l}\text { High intensity pulsed Xenon } \\
\text { lamp that provides a broadband } \\
\text { spectrum from 190nm to } \\
1100 \mathrm{~nm} \\
\text { Adjustable energy up to } 2000 \\
\text { Joules/pulse } \\
\text { Selectable pulse duration: } 100 \text { to } \\
2000 \mu \mathrm{s} \\
\text { Adjustable pulse energy: } 200-\end{array}$ \\
\hline
\end{tabular}




\begin{tabular}{|c|c|c|c|}
\hline & & & $\begin{array}{l}2000 \text { Joules } \\
\text { UV Sintering area: } 1.9 \times 30.5 \mathrm{~cm}\end{array}$ \\
\hline 3D Printing & BSU & Kudo 3D DLP - SLA & $\begin{array}{l}\text { XY resolution: } 26 \mu \mathrm{m} \sim 50 \mu \mathrm{m} \\
Z \text { resolution: } 5 \mu \mathrm{m} \\
\text { Build Size: XY } 50 \mu \mathrm{m} \text { resolution: } \\
3.7 \text { in x } 2.1 \text { in } x 9.8 \text { in } \\
\text { Maximum print speed: }>2.7 \\
\text { inches / hr for xy: } 50 \mu \mathrm{m} \text { and } \mathrm{z} \text { : } \\
100 \mu \mathrm{m} \text { resolution } \\
\text { Hard and tough resin inks }\end{array}$ \\
\hline 3D Printing & BSU & 3D Systems Viper 2 SLA & $\begin{array}{l}\text { Build layer capability (z-axis): } \\
\text { Minimum - } 0.02 \mathrm{~mm} \text {; Typical - } \\
0.05 \mathrm{~mm} \\
\text { Vertical resolution } 0.025 \mathrm{~mm} \\
\text { Position repeatability } 0.0076 \mathrm{~mm} \\
\text { Maximum part weight } 9.1 \mathrm{~kg} \\
\text { Typical velocity during part } \\
\text { building } 5 \mathrm{~mm} / \mathrm{sec} \\
\mathrm{Accura}^{\mathrm{SI}} 10 \text { polymer } \\
\mathrm{Al}_{2} \mathrm{O}_{3} \text { loaded monomer } \\
\text { suspension }\end{array}$ \\
\hline $\begin{array}{l}\text { Micro/ } \\
\text { Nanofabricati } \\
\text { on }\end{array}$ & BSU & AJA Orion 5 Sputtering Machine & $\begin{array}{l}\text { Physical Vapor Deposition } \\
\text { system with RF and DC target } \\
\text { sputtering capability. } 100 \mathrm{~mm} \\
\text { tooling, heated substrate, load } \\
\text { lock, film thickness monitor, } \\
\text { substrate biasing. }\end{array}$ \\
\hline $\begin{array}{l}\text { Micro/ } \\
\text { Nanofabricati } \\
\text { on }\end{array}$ & BSU & CHA 600 Thermal Evaporator & $\begin{array}{l}\text { It can deposit materials with a } \\
\text { specified thickness of up to } 1500 \\
\text { nanometers. Three } 8 \text { " wafers can } \\
\text { be processed simultaneously and } \\
\text { tooling is being developed for } \\
\text { additional sizes. Up to three } \\
\text { different layers may be } \\
\text { evaporated in one run. }\end{array}$ \\
\hline $\begin{array}{l}\text { Micro/ } \\
\text { Nanofabricati } \\
\text { on }\end{array}$ & BSU & Quintel Q-4000 Contact Aligner & $\begin{array}{l}\text { UV light source patterning with } \\
\text { contact or proximity printing. } \\
\text { Use with mask geometries of } \\
5 \times 5 \times 90 \text { mil. } 1 \text { micron resolution. }\end{array}$ \\
\hline $\begin{array}{l}\text { Micro/ } \\
\text { Nanofabricati } \\
\text { on }\end{array}$ & BSU & FEI Teneo FESEM w/Nabity NPGS & $\begin{array}{l}<100 \mathrm{~nm} \text { patterning depending } \\
\text { on process conditions }\end{array}$ \\
\hline $\begin{array}{l}\text { X-ray micro- } \\
\text { CT }\end{array}$ & BSU & Skyscan 1172 Micro-CT scanner & $\begin{array}{l}\text { X-ray source of } 20-100 \mathrm{~V}, 10 \mathrm{~W}, \\
<5 \mu \mathrm{m} \text { spot size or } 20-80 \mathrm{~V}, 8 \mathrm{~W} \text {, } \\
<8 \mu \mathrm{m} \text { spot size, has a fully } \\
\text { distortion-corrected } 11 \mathrm{Mp} \text { X-ray } \\
\text { detector that is a } 12 \text {-bit cooled } \\
\text { CCD fiber-optically camera } \\
\text { coupled to scintillator }\end{array}$ \\
\hline
\end{tabular}




\begin{tabular}{|c|c|c|c|}
\hline $\begin{array}{l}\text { Nuclear } \\
\text { Magnetic } \\
\text { Resonance }\end{array}$ & BSU & Bruker IPSO $300 \mathrm{MHz}$ NMR & $\mathrm{BBO}$ probe \\
\hline $\begin{array}{l}\text { Nuclear } \\
\text { Magnetic } \\
\text { Resonance }\end{array}$ & BSU & Bruker AVANCE III 600MHz NMR & $\begin{array}{l}\text { Liquids (BBO, TXIm TCI } \\
\text { cryoprobe) and solids }(4 \mathrm{~mm} \\
\text { MAS) probes }\end{array}$ \\
\hline Microscopy & $\mathrm{BSU}$ & Scanning electron microscope & $\begin{array}{l}\text { Contains detectors for EBSD, } \\
\text { EDS, FESEM and EMPA }\end{array}$ \\
\hline $\begin{array}{l}\text { Surface } \\
\text { science }\end{array}$ & $\mathrm{BSU}$ & Atomic Force Microscope (AFM) & $\begin{array}{l}\text { Three available machines, each } \\
\text { located on isolated concrete slabs } \\
\text { and vibration isolation tables. }\end{array}$ \\
\hline $\begin{array}{l}\text { Computational } \\
\text { Resources }\end{array}$ & $\mathrm{BSU}$ & High Performance Computing Clusters & $\begin{array}{l}\text { The R1 cluster, a Linux core } \\
\text { operating system (CentOS 5.2) } \\
\text { supporting } 16 \text { computer nodes, } \\
\text { each with } 32 \text { AMD Opteron } \\
61288 \text { core CPUs, for a total of } \\
256 \text { CPU cores. Five compute } \\
\text { nodes with dual T-2050's GPU } \\
\text { cards, and } 3 \text { compute nodes with } \\
\text { GTX680 GPU cards. Each GPU } \\
\text { has } 448 \text { cores. } \\
\text { The R } 2 \text { computer cluster: } 22 \\
\text { node GPU/CPU cluster, each } \\
\text { node consists of dual } 14-c o r e \\
\text { Intel processors and eight nodes } \\
\text { provide NVIDIA P100 GPUs } \\
\text { The Fry cluster provides } 28 \\
\text { NVIDIA Pascal P100 GPUs }\end{array}$ \\
\hline $\begin{array}{l}\text { Additive } \\
\text { Manufacturing }\end{array}$ & UND & Optomec aerosol jet 300 printer & \\
\hline $\begin{array}{l}\text { Additive } \\
\text { Manufacturing }\end{array}$ & UND & $\begin{array}{l}\text { XENON S-2100 pulsed light sintering } \\
\text { equipment }\end{array}$ & \\
\hline $\begin{array}{l}\text { Materials } \\
\text { Fabrication }\end{array}$ & UND & $\begin{array}{l}\text { Wet-chemistry bench, lab hood } \\
\text { Vacuum sintering furnace }\end{array}$ & \\
\hline $\begin{array}{l}\text { Materials } \\
\text { Characterizati } \\
\text { on }\end{array}$ & UND & $\begin{array}{l}\text { Custom-built scanning thermal probe } \\
\text { microscope }\end{array}$ & \\
\hline $\begin{array}{l}\text { Materials } \\
\text { Characterizati } \\
\text { on }\end{array}$ & UND & $\begin{array}{l}\text { Vacuum cryostat and lock-in amplifier for } \\
\text { thermal conductivity measurement }\end{array}$ & \\
\hline $\begin{array}{l}\text { Device } \\
\text { Fabrication/ } \\
\text { Testing }\end{array}$ & UND & $\begin{array}{l}\text { Vacuum brazing furnace } \\
\text { Inert gas soldering stations } \\
\text { Custom thermoelectric device testing system }\end{array}$ & \\
\hline Software & UND & ANSYS Multiphysics simulation software & For device design and simulation \\
\hline $\begin{array}{l}\text { Material } \\
\text { Deposition }\end{array}$ & UND & $\begin{array}{l}\text { Denton Explorer electron-beam evaporator } \\
\text { Emitech K675X 3-target, Peltier-cooled }\end{array}$ & \\
\hline
\end{tabular}




\begin{tabular}{|c|c|c|c|}
\hline & & $\begin{array}{l}\text { sputtering system } \\
\text { Airco FC-1800 multi-pocket electron-beam } \\
\text { evaporators (3) } \\
\text { First Nano 3-tube, low-pressure chemical } \\
\text { vapor deposition (LPCVD) system } \\
\text { General Air atmospheric-pressure CVD } \\
\text { (APCVD) system } \\
\text { Oerlikon Leybold 5-target UHV sputtering } \\
\text { system } \\
\text { Oerlikon Leybold 3-chamber, 16-target UHV } \\
\text { sputtering system for magnetic materials } \\
\text { Oerlikon Leybold 8-pocket electron-beam, } \\
\text { dual thermal evaporation system } \\
\text { Oxford FlexAL remote plasma and thermal } \\
\text { ALD system } \\
\text { Perkin-Elmer RF, DC magnetron, 8-inch, 3- } \\
\text { target sputter deposition system } \\
\text { Cambridge Nanotech Savannah atomic layer } \\
\text { deposition (ALD) system } \\
\text { Unaxis } 790 \text { plasma-enhanced chemical vapor } \\
\text { deposition (PECVD) system } \\
\text { Varian thermal deposition system } \\
\text { Veeco evaporator }\end{array}$ & \\
\hline Etching & UND & $\begin{array}{l}\text { Alcatel } 601 \mathrm{E} \text { inductively coupled plasma } \\
\text { reactive ion etch (ICP-RIE) system } \\
\text { Drytek RF plasma asher } \\
\text { MemsStar BT001 xenon difluoride (XeF2) } \\
\text { etch system } \\
\text { Oerlikon Shuttleline ICP-RIE system with } \\
\text { endpoint system } \\
\text { Oxford PlasmaPro System } 100 \text { ICP-RIE } \\
\text { system with endpoint system } \\
\text { Plasmatherm } 790 \text { RIE } \\
\text { PVA PS210 microwave plasma asher } \\
\text { Tegal barrel asher } \\
\text { UVO cleaner }\end{array}$ & \\
\hline $\begin{array}{l}\text { General } \\
\text { Fabrication }\end{array}$ & UND & $\begin{array}{l}\text { Allied Multiprep CMP system } \\
\text { Allwin AccuThermo AW610 Rapid Thermal } \\
\text { Processing (RTP) System } \\
\text { Logitech Orbis chemical-mechanical } \\
\text { polishing system (CMP), Type 1CM62 } \\
\text { Six Thermco furnace tubes (oxidation } \\
\text { diffusion) }\end{array}$ & \\
\hline Lithography & UND & $\begin{array}{l}\text { Cobilt CA- } 800 \text { wafer-to-mask alignment and } \\
\text { exposure system } \\
\text { RTS AutoStep } 200 \\
\text { RTS Mann } 3600 \mathrm{~F} \text { pattern generator } \\
\text { Lindberg/BlueM resist baking oven } \\
\text { OAI light source }\end{array}$ & \\
\hline
\end{tabular}




\begin{tabular}{|c|c|c|}
\hline & & $\begin{array}{l}\text { SUSS MJB } 3 \text { mask aligner (2) } \\
\text { Tamarack Series } 142 \text { contact printer } \\
\text { Vistec EBPG } 5200 \text { electron beam } \\
\text { lithography system }\end{array}$ \\
\hline Metrology & UND & $\begin{array}{l}\text { Agilent B1500 semiconductor parameter } \\
\text { analyzer with I-V and capacitance-voltage } \\
\text { modules } \\
\text { Tencor Alphastep model } 500 \text { surface } \\
\text { profilometer } \\
\text { Cascade Microtech M150 test station } \\
\text { Filmetrics film thickness measurement } \\
\text { system (spectral reflectance) } \\
\text { Four-point resistivity probe } \\
\text { Veeco FPP-5000 automatic four-point probe } \\
\text { Gaertner ellipsometer } \\
\text { Hitachi S-4500 field emission scanning } \\
\text { electron microscope } \\
\text { KLA/Tencor P-6 profilometer } \\
\text { Olympus LEXT OLS4100 confocal } \\
\text { microscope } \\
\text { Olympus optical microscopes (4) } \\
\text { Metricon prism coupler } \\
\text { J. A. Woollam variable-angle spectroscopic } \\
\text { ellipsometer (VASE) }\end{array}$ \\
\hline $\begin{array}{l}\text { Microscopy/M } \\
\text { aterials } \\
\text { Characterizati } \\
\text { on }\end{array}$ & UND & $\begin{array}{l}\text { TEM: Titan 80-300 (FEI) } \\
\text { TEM: JEOL } 2011 \\
\text { Electron Probe Analyzer: Cameca SX-50 } \\
\text { FESEM: Magellan } 400 \text { (FEI) } \\
\text { Helios NanoLabTM Dual Beam } 600 \\
\text { SEM/FIB Workstation: Helios NanoLab } \\
\text { DualBeam } 600 \text { (FEI) } \\
\text { Environmental SEM: EVO } 50 \text { LEO (Carl } \\
\text { Zeiss) } \\
\text { Synthesis } \\
\text { Microwave Reactor } \\
\text { Thermal Evaporator } \\
\text { Surface and Thermal Analysis } \\
\text { Adsorption (BET/Chemi- and Physi- } \\
\text { sorption) (Micromeritics) } \\
\text { Atomic Force Microscope (AFM Park XE7) } \\
\text { Differential Scanning Calorimeter (Setaram) } \\
\text { TGA/DSC-Mass Spectrometer (Mettler } \\
\text { Toledo / Pfeiffer) } \\
\text { Profilometer (Bruker) } \\
\text { X-Ray Photo-electron Spectrometer (XPS) }\end{array}$ \\
\hline
\end{tabular}




\begin{tabular}{|l|l|l|}
\hline & Spectroscopy & FTIR Spectrometer equipped with ATR and \\
& Diffuse reflectance accessory (Jasco) & \\
Fourier Transform Infrared Spectroscopy & \\
Microscope (Spotlight 200 Perkin Elmer) & \\
& UV-VIS-NIR Absorbance (Jasco) \\
& Raman (Point and Mapping) (Jasco / Bruker) & \\
Solar Simulators (2 Xe lamps - 150W ozone & \\
& free, and 300W) & \\
& Photocatalyst and Electro-chemical Testing & \\
& Stations & \\
& Solar Simulator & \\
& In-Line Gas Chromatography & \\
\hline
\end{tabular}




\section{Appendix B}

Table B1: In-hand capabilities and needs for advanced manufacturing of sensor across all work packages in the In-Pile Initiative

\begin{tabular}{|c|c|c|c|}
\hline $\begin{array}{l}\text { Work Package/ } \\
\text { Sensor }\end{array}$ & Specifications & $\begin{array}{l}\text { Required AM } \\
\text { Infrastructure }\end{array}$ & AM Gap \\
\hline $\begin{array}{l}\text { WP2/Field } \\
\text { Properties/Printed } \\
\text { Neutron Dosimeters }\end{array}$ & $\begin{array}{l}\text { - Sample size } \sim 1 \mathrm{~cm} \mathrm{x} 1 \\
\mathrm{~cm} \text { area } \\
\text { - } 2 \mathrm{mg} \text { of deposited } \\
\text { material }+/-0.2 \mathrm{mg} \\
\text { - } 10 \text { elemental inks } \\
\text { - Detect thermal and fast } \\
\text { neutrons }\end{array}$ & $\begin{array}{l}\text { - AJP - } 200 \\
\text { - Dimatix } 2831 \\
\text { - Xenon Sinteron } 2100\end{array}$ & $\begin{array}{l}\text { - Elemental } \\
\text { nanoparticle inks } \\
\text { compatible with } \\
\text { additive } \\
\text { manufacturing } \\
\text { - Irradiation testing of } \\
\text { elemental nanoparticle } \\
\text { inks }\end{array}$ \\
\hline $\begin{array}{l}\text { WP2/ Field } \\
\text { Properties/Passive } \\
\text { Temperature } \\
\text { Monitors }\end{array}$ & $\begin{array}{l}\text { - Sample size } \sim 2 \mathrm{~cm} \mathrm{x} 2 \\
\text { cm area } \\
\text { - Sense peak } \\
\text { temperatures from } 100 \\
{ }^{\circ} \mathrm{C} \text { to } 1500{ }^{\circ} \mathrm{C} \text { in a } 50 \\
{ }^{\circ} \mathrm{C} \text { step } \\
\text { - Tolerate neutron flux: } \\
\text { Thermal: } 1 \times 10^{15} \\
\mathrm{n} / \mathrm{cm}^{2}-\mathrm{s} \\
\text { Fast: up to } 5 \times 10^{14} \\
\mathrm{n} / \mathrm{cm}^{2}-\mathrm{s}(\mathrm{E}>0.1 \mathrm{MeV}) \\
\text { for up to } 1 \text { year. } \\
\text { - Compatible with } \\
\text { Electrical readout }\end{array}$ & $\begin{array}{l}\text { - AJP - } 200 \\
\text { - Dimatix } 2831 \\
\text { - Xenon Sinteron } 2100 \\
\text { - AJA Orion } 5 \text { Sputtering } \\
\text { Machine } \\
\text { - } \text { Quintel Q-4000 Contact } \\
\text { Aligner }\end{array}$ & $\begin{array}{l}\text { - Elemental and alloyed } \\
\text { nanoparticle inks } \\
\text { compatible with } \\
\text { additive } \\
\text { manufacturing } \\
\text { - Irradiation testing of } \\
\text { printed passive sensors } \\
\text { - Modeling and } \\
\text { simulation support to } \\
\text { develop AM process } \\
\text { control parameters }\end{array}$ \\
\hline $\begin{array}{l}\text { WP2/ Field } \\
\text { Properties/High } \\
\text { Temperature } \\
\text { Irradiation Resistant } \\
\text { Thermocouples }\end{array}$ & $\begin{array}{l}\text { - Sense up to } 1600^{\circ} \mathrm{C} \\
+/-2^{\circ} \text { accuracy } \\
\text { - Tolerate neutron flux: } \\
\text { Thermal: } 1 \times 10^{15} \\
\text { n/cm } / \mathrm{cm}^{2} \mathrm{~s} \\
\text { Fast: up to } 5 \times 10^{14} \\
\mathrm{n} / \mathrm{cm}^{2} \text {-s }(\mathrm{E}>0.1 \mathrm{MeV}) \\
\text { for up to } 1 \text { year }\end{array}$ & $\begin{array}{l}\text { - AJP - } 200 \\
\text { - Dimatix } 2831 \\
\text { - Xenon Sinteron } 2100 \\
\text { - AJA Orion } 5 \text { Sputtering } \\
\text { Machine } \\
\text { - } \text { Quintel Q-4000 Contact } \\
\text { Aligner }\end{array}$ & $\begin{array}{l}\text { - Materials design HTIR } \\
\text { thermocouples } \\
\text { - Irradiation testing of } \\
\text { HTIR thermocouples } \\
\text { - Micro/Nanofabrication } \\
\text { of HTIR } \\
\text { thermocouples }\end{array}$ \\
\hline $\begin{array}{l}\text { WP5/Thermal } \\
\text { Properties/Advanced } \\
\text { Needle Probe }\end{array}$ & $\begin{array}{l}\text { - Measure thermal } \\
\text { conductivity from } \\
\text { room temperature up } \\
\text { to } 1800^{\circ} \mathrm{C} \text { with }+/-5 \\
\mathrm{~W} / \mathrm{m} / \mathrm{K} \text { accuracy } \\
\text { - Tolerate neutron flux: } \\
\text { Thermal: } 1 \times 10^{15} \\
\text { n/cm }{ }^{2} \text {-s } \\
\text { Fast: up to } 5 \times 10^{14} \\
\text { n/cm }{ }^{2}-\mathrm{s}(\mathrm{E}>0.1 \mathrm{MeV}) \\
\text { for up to } 1 \text { year }\end{array}$ & $\begin{array}{l}\text { - AJP - } 200 \\
\text { - Dimatix } 2831 \\
\text { - Xenon Sinteron } 2100 \\
\text { - Quintel Q-4000 Contact } \\
\text { Aligner } \\
\text { - AJA Orion } 5 \text { Sputtering } \\
\text { Machine } \\
\text { - FEI Teneo FESEM } \\
\text { w/Nabity NPGS }\end{array}$ & $\begin{array}{l}\text { - } \text { Materials design } \\
\text { needle probe sensor } \\
\text { - Irradiation testing of } \\
\text { needle probe sensor } \\
\text { - Micro/Nanofabrication } \\
\text { of needle probe HTIR } \\
\text { thermocouples }\end{array}$ \\
\hline
\end{tabular}

Appendix C 
Table C1: Identified advanced manufacturing needs for acquisition to augment current capabilities for sensors development across all work packages in the In-Pile Initiative

\begin{tabular}{|c|c|c|c|}
\hline $\begin{array}{l}\text { Work Package/ } \\
\text { Sensor }\end{array}$ & Specifications & $\begin{array}{l}\text { Required AM } \\
\text { Infrastructure }\end{array}$ & AM Gap \\
\hline $\begin{array}{l}\text { WP5/Thermal } \\
\text { Properties/3 - } \\
\text { omega Thermal } \\
\text { Conductivity Sensor }\end{array}$ & $\begin{array}{l}\text { - Measure thermal } \\
\text { conductivity from } \\
\text { room temperature up } \\
\text { to } 1800^{\circ} \mathrm{C} \text { with }+/-5 \\
\mathrm{~W} / \mathrm{m} / \mathrm{K} \text { accuracy } \\
\text { - Print conformal } \\
\text { sensors on } 5 \mathrm{~mm} \\
\text { radius of curvature } \\
\text { - Tolerate neutron flux: } \\
\text { Thermal: } 1 \times 10^{15} \\
\mathrm{n} / \mathrm{cm}^{2}-\mathrm{s} \\
\text { Fast: up to } 5 \times 10^{14} \\
\mathrm{n} / \mathrm{cm}^{2}-\mathrm{s}(\mathrm{E}>0.1 \mathrm{MeV}) \\
\text { for up to } 1 \text { year }\end{array}$ & $\begin{array}{l}-\mathrm{AJP}-5 \mathrm{X} \\
\text { (along with Xenon Sinteron } \\
2100 \text { ) }\end{array}$ & $\begin{array}{l}\text { - Elemental and alloyed } \\
\text { nanoparticle inks } \\
\text { compatible with } \\
\text { additive } \\
\text { manufacturing } \\
\text { - Irradiation testing of } \\
\text { printed passive sensors } \\
\text { - Modeling and } \\
\text { simulation support to } \\
\text { develop AM process } \\
\text { control parameters } \\
\text { - Conformal printing } \\
\text { capability }\end{array}$ \\
\hline $\begin{array}{l}\text { WP5/Thermal } \\
\text { Properties/3- } \\
\text { omega Thermal } \\
\text { Conductivity Sensor }\end{array}$ & $\begin{array}{l}\text { - Measure thermal } \\
\text { conductivity from } \\
\text { room temperature up } \\
\text { to } 1800^{\circ} \mathrm{C} \text { with }+/-5 \\
\mathrm{~W} / \mathrm{m} / \mathrm{K} \text { accuracy } \\
\text { - Print conformal } \\
\text { sensors on } 5 \mathrm{~mm} \\
\text { radius of curvature } \\
\text { - Tolerate neutron flux: } \\
\text { Thermal: } 1 \times 10^{15} \\
\mathrm{n} / \mathrm{cm}^{2}-\mathrm{s} \\
\text { Fast: up to } 5 \times 10^{14} \\
\mathrm{n} / \mathrm{cm}^{2}-\mathrm{s}(\mathrm{E}>0.1 \mathrm{MeV}) \\
\text { for up to } 1 \text { year }\end{array}$ & LENS System & $\begin{array}{l}\text { - Fabrication of thin } \\
\text { wires and needle } \\
\text { probes for sensors }\end{array}$ \\
\hline $\begin{array}{l}\text { WP8/Mechanical } \\
\text { Properties/Printed } \\
\text { Capacitive Strain } \\
\text { Gauge }\end{array}$ & $\begin{array}{l}\text { - Measure strain from } \\
0 \% \text { to } 20 \% \text { with }+/- \\
0.2 \% \text { accuracy } \\
\text { - Print conformal } \\
\text { sensors on } 5 \mathrm{~mm} \\
\text { radius of curvature } \\
\text { electrically passivated } \\
\text { metallic surface } \\
\text { - Tolerate neutron flux: } \\
\text { Thermal: } 1 \times 10^{15} \\
\text { n/cm }{ }^{2}-\mathrm{s} \\
\text { Fast: up to } 5 \times 10^{14} \\
\mathrm{n} / \mathrm{cm}^{2}-\mathrm{s}(\mathrm{E}>0.1 \mathrm{MeV}) \\
\text { for up to } 1 \text { year }\end{array}$ & $\begin{array}{l}-\mathrm{AJP}-5 \mathrm{X} \\
\text { (along with Xenon Sinteron } \\
2100 \text { ) }\end{array}$ & $\begin{array}{l}\text { - Elemental and alloyed } \\
\text { nanoparticle inks } \\
\text { compatible with } \\
\text { additive } \\
\text { manufacturing } \\
\text { - Irradiation testing of } \\
\text { printed passive sensors } \\
\text { - Modeling and } \\
\text { simulation support to } \\
\text { develop AM process } \\
\text { control parameters } \\
\text { - Conformal printing } \\
\text { capability }\end{array}$ \\
\hline
\end{tabular}

